\title{
Robust optima and tolerance ranges of biological indicators: a new method to identify sentinels of global warming
}

Received: 16 May 2013/ Accepted: 4 November 2013/Published online: 7 December 2013 (C) The Ecological Society of Japan 2013

\begin{abstract}
This study aims to introduce the robust optimum (RO) method as an alternative to the classical weighted averaging (WA) method for estimating the ecological optimum as well as the optimum and tolerance ranges of a taxon with respect to an environmental variable in limnological studies. The RO method is based on robust location and scale estimates rather than on the mean and the standard deviation used by the WA method. The results of our study support the well-known fact that the presence of outliers and the asymmetry of the distribution of the environmental variable might cause a significant effect on the WA-calculated ecological optimum as well as on tolerance ranges. We compared both methods through the identification of potential biological indicators of global warming. Biological data included several benthic, oligostenotherm macroinvertebrate families inhabiting the Júcar River Basin (JRB, eastern Spain). The results of this comparison suggest that the RO method is more appropriate for estimating the distribution of taxa and, consequently, that it provides more realistic information for identifying potential sentinels of global warming in running aquatic systems. Currently, the identification of such sentinels is a goal for several environmental protection laws, such as the European Union Water Framework Directive.
\end{abstract}

E. Cristóbal · S. V. Ayuso · M. Toro

Área de Medio Ambiente Hídrico, Centro de Estudios

Hidrográficos, CEDEX, 28005 Madrid, Spain

E. Cristóbal ( $\square)$

Área de Modelos Numéricos, Centro de Estudios de Puertos

y Costas, CEDEX, 28026 Madrid, Spain

E-mail: elena.cristobal@cedex.es

Tel.: + 34-913357660

Fax: + 34-913357601

S. V. Ayuso

Grupo de Ecología Funcional, Instituto del Agua,

Universidad de Granada, 18071 Granada, Spain

A. Justel

Departamento de Matemáticas, Universidad Autónoma

de Madrid, 28049 Madrid, Spain
Keywords Ecological optima - Optimum range

Tolerance range $\cdot$ Box-plot $\cdot$ Global warming $\cdot$

Biological indicator $\cdot$ EU-WFD

\section{Introduction}

The ecological optimum can be defined as a certain combination of environmental variables that is optimal for the existence, development, growth and reproduction of a taxon (Verbitsky and Verbitskaya 2007). This definition is therefore very similar to that proposed by Hutchinson (1957) for the term ecological niche. Each environmental variable constituting the ecological optimum can be plotted on an axis and can be thought of as a dimension in a space (Wetzel 2001). Hence, in one dimension, the ecological optimum can be defined as the value of the environmental variable in which the taxon thrives best (Ter Braak and van Dam 1989). However, in natural ecosystems, the ecological optimum includes not only a single point, but also the oscillations of the environmental variable around this point, i.e. the optimum range or the effective ecological epicentre. Furthermore, for each environmental variable, there are lower and upper limits, below and above which, the taxon cannot survive because the environmental conditions are unfavourable. These limits constitute the tolerance range of the taxon. Close to its tolerance limits, the taxon goes into a physiological stress area (Huggett 2004). Tolerance ranges are usually characterised as narrow or broad. The narrower the range, the more specialised the taxon (Smith and Smith 2009).

To compute and represent the ecological optimum and the tolerance range of a specific taxon in one dimension, the weighted averaging (WA) method (Ter Braak and Barendregt 1986) has been traditionally used. This is a probabilistic method that consists of studying the distribution of the potential values that the environmental variable can take in the population of a specific taxon. The idea behind the WA method is to define the ecological optimum as the central value of the 
distribution and the tolerance range as the dispersion measured with the standard deviation. The WA method has been utilised commonly in paleolimnology to estimate past conditions using transfer functions (Oksanen et al. 1988; Birks et al. 1990; Bradshaw et al. 2002; Miettinen et al. 2005; Holden et al. 2008), as well as for assessing the trophic state of lakes and reservoirs (Schoenfelder et al. 2002; Negro and de Hoyos 2005; Yang et al. 2008).

The first objective of this work was to introduce a new method for computing and representing ecological optima as well as tolerance ranges and optimum ranges of taxa. The new method is called the robust optimum (RO) method and should be considered as an alternative to overcome the well-known limitations of the classical WA method for estimating the ecological optimum and the tolerance range of a taxon with regard to an environmental variable.

The second objective of this work was to compare the WA method with the RO method by calculating and representing ecological optima, optimum ranges and tolerance ranges for several families of benthic macroinvertebrates inhabiting the Júcar River Basin (JRB, eastern Spain) with respect to real water temperature data as well as to four simulated increases in water temperature. The comparison through a simulation of increases in water temperature will allow identifying potential biological indicators of global warming among the families of benthic macroinvertebrates. Currently, the identification of potential biological indicators of global warming constitutes an important goal in many environmental protection laws and programmes, mainly because there is a high confidence that observed changes in freshwater ecosystems and their biological communities are associated with rising water temperatures (IPCC 2007; Woodward et al. 2010). In fact, freshwater systems in general, and rivers in particular, are probably the most threatened systems of all (Abell 2002). A good biological indicator is a biological element that should respond rapidly and clearly to natural and anthropogenic disturbances and stressors (Ter Braak and Looman 1986; Cairns et al. 1993; Wright et al. 2006). Since a reliable biological indicator must have both a well-defined ecological optimum and a narrow tolerance range (Reed 1998; Negro and de Hoyos 2005), it is absolutely essential to assess the correctness of both methods (WA and $\mathrm{RO}$ ) for estimating accurate values of ecological optima, optimum ranges and tolerance ranges. This knowledge will improve the prediction of the potential impacts of global warming on aquatic systems, according to the objectives established by the European Union Water Framework Directive (EU-WFD) (EC 2000). This improvement would allow preventing further ecological deterioration provoked by natural and anthropogenic disturbances and stressors, while at the same time protecting and enhancing the ecological status of aquatic ecosystems and, with regard to their water needs, of terrestrial ecosystems and wetlands depending directly on aquatic ecosystems.

\section{Materials and methods}

\section{Study area}

The JRB in eastern Spain is managed by the Júcar River Basin Authority (JRBA), and is made up of a group of different small river basins covering a total area of around $43,000 \mathrm{~km}^{2}$ (Fig. 1) (Estrela et al. 2004). The Spanish authorities selected the JRB as the pilot river basin pursuant to the EU-WFD (EC 2000). The JRB, due to its landscape, is characterised by diverse climates and landforms. Its major geomorphic features include several mountain ranges, a continental plateau and a coastal plain. The orography of the territory favours the discharge of water into the Mediterranean Sea and thus the formation of small river basins. All the rivers within the JRB therefore flow into this sea. A mountain range called the Iberian System runs northwest to southeast across the JRB. The highest peak in the JRB is located in this range [2,012 $\mathrm{m}$ above sea level (m a.s.l.)]. The Iberian System is very important for the water resources of the JRB because it acts as a barrier for ocean fronts, forcing humid clouds to rise towards upper, colder layers of the atmosphere. Once the air is lifted and cooled, the moisture falls as rain. A small part of another mountain range, called the Betic System, extends over the southeast territory of the JRB. This mountain area plays an important role in the water supply of the southern part of the JRB. The continental plateau is characterised by having a relatively flat surface with an average height of $650 \mathrm{~m}$ a.s.l., and is located in the western part of the JRB between the aforementioned mountain ranges. A large aquifer system is located in this plateau. The aquifer and the JRB highly influence each other in terms of draining and recharge. The coastal plain is an alluvial platform along the strip coast. This plain has the Iberian System in the northwest part, the continental plateau in the west and the Betic System in the south. The coastal plain provides a very rich soil that supports the vast majority of agriculture production in the JRB. Although the climate of the JRB is predominantly Mediterranean, with hot, dry summers and mild winters, certain continental climatic features can be found in areas located far from the coastline. The long periods of sunshine, along with the circulation of hot air masses, give rise to high temperatures, with mean annual values of $9{ }^{\circ} \mathrm{C}$ in mountain areas and $18{ }^{\circ} \mathrm{C}$ in the coastal plain. Rainfall in the JRB shows a high spatial and temporal variability. The mean annual precipitation in the basin is $504 \mathrm{~mm}$, ranging from $300 \mathrm{~mm}$ in the driest years to $700 \mathrm{~mm}$ in the wettest. Mean annual rainfall values in the JRB vary from $250 \mathrm{~mm}$ in the south to $900 \mathrm{~mm}$ in the north. This is because the basin is located between two different climatic regions, the European and the North African, which generates differentiated responses in the behaviour of the weather within the JRB. Rainfall occurs primarily between October and April. However, severe rainfall events can 


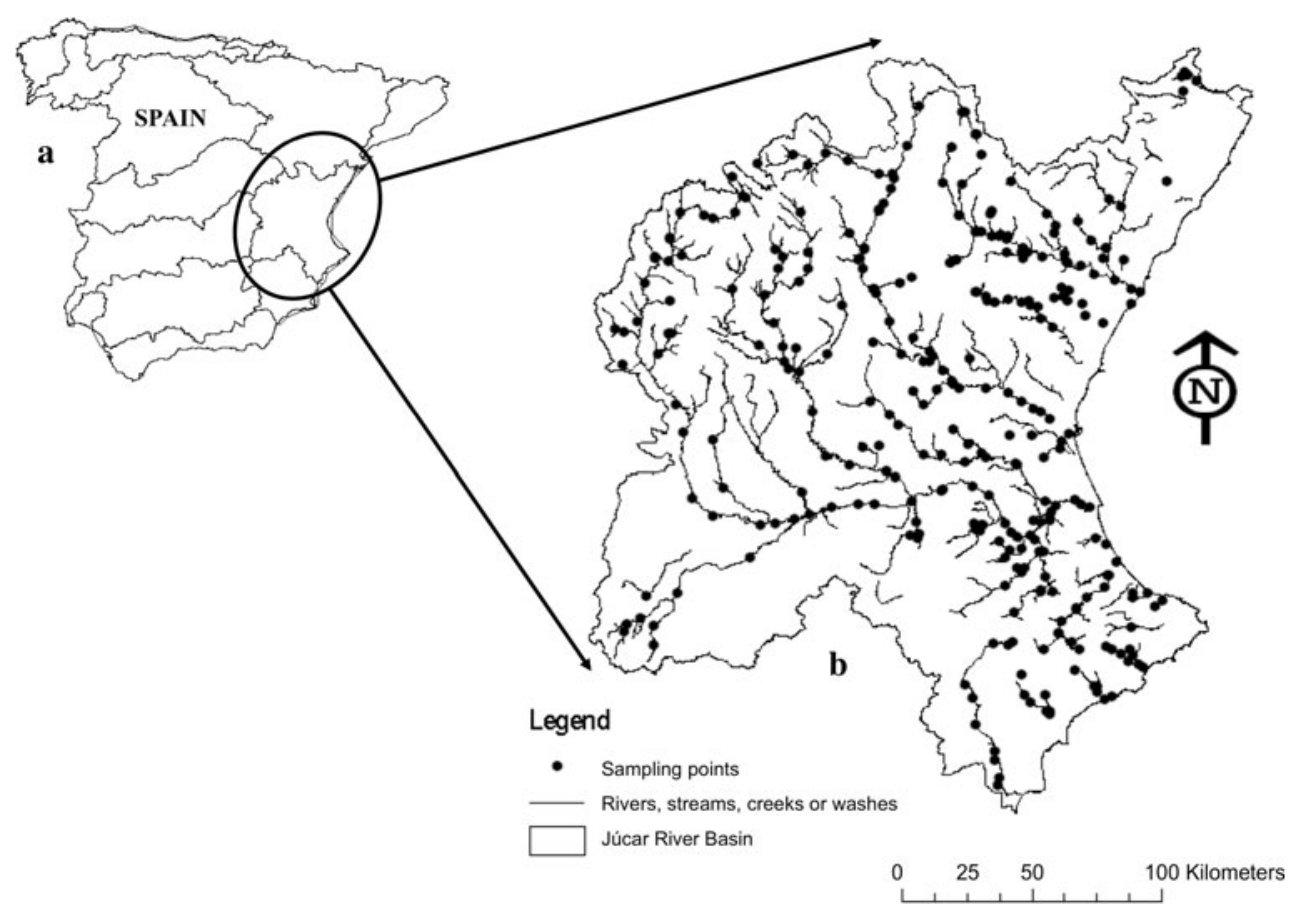

Fig. 1 a Spanish River basin districts. b Sampling stations located in the Júcar River Basin (JRB)

occur during late summer, generating high flows in ephemeral creeks located in the southeast part of the basin. According to the UNESCO climatic index, there are three types of climatic regions in the JRB: semiarid, sub-humid and humid. Carbonate and evaporative materials clearly dominate over siliceous materials in the JRB. Calcarenites and marls dominate the JRB, though significant proportions of limestone and alluvial material are also found, mainly in the areas close to the mouths of the main rivers. Land uses have changed over time. Currently, the area of the JRB features well-preserved forest and wetlands along with agricultural crops and urban and industrialised zones. The dominant land use is forest and semi natural areas, which cover $50 \%$ of the territory. This use is followed by agricultural nonirrigated and agriculture-irrigated areas of the territory, which cover $40 \%$ and $8 \%$ of the area, respectively. Urban and industrial zones cover $1.8 \%$ of the territory, with wetlands covering just $0.2 \%$ of the JRB.

Sampling stations, macroinvertebrate data and water temperature data

Three hundred and ten sampling stations were sampled during a 7-year period (1999-2006) (Fig. 1). The sampling stations are managed by the staff of the JRB and were used previously, along with other sampling stations located throughout Spain, to describe specific physical, chemical and geomorphological properties of different bodies of running waters present in the country, according to the objectives established by the EU-WFD (EC 2000). The general characterisation of these bodies was the first step toward classifying them into several types. A total of 32 river types were defined in Spain, 9 of which are found in the JRB (type numbers 5, 9, 10, 12, 13, 14, 16, 17 and 18) (MARM 2008). The number and the name of the type of river, as well as the ranges and thresholds of several variables that specifically define the different types of rivers found not only in the JRB but also in other Spanish river basins, are summarised in Table 1. Finally, it is important to note that not only sampling stations ranked at least as 'good' were used in this study. We also used sampling stations included in one out of the four other categories of ecological status established by the EU-WFD (EC 2000).

Data on aquatic macroinvertebrate families were obtained from the 310 sampling stations managed by the staff of the JRB (Fig. 1). At least 170 out of the 310 sampling stations were sampled seasonally (spring and autumn) during a 7-year period (1999-2006). Each sampling station is representative of its stretch of the river and includes all the habitats characteristic of the stream where it is located. Biological samples were taken following the methodology described by Jáimez-Cuéllar et al. (2002). Briefly, by using a hand net $(500 \mu \mathrm{m}$ mesh size), all available habitats per site (100-m long stations) were sampled until no more families were identified in situ. This methodology was developed to achieve the objectives established by the EU-WFD (EC 2000). Aquatic macroinvertebrates were identified, classified and counted (at least 200 organisms per sample were 
counted for absolute abundances) by the staff of the JRB; 115 different families were found. Only family-level macroinvertebrate data were used in this study, in keeping with the Iberian Bio-Monitoring Working Party (IBMWP) methodology adopted for the classification and the assessment of the ecological status of Spanish running waters, following the requirements established by the EU-WFD (EC 2000).

The staff of the JRB measured the temperature of the water $(T)$ with a WTW 340i handheld multi-parameter device (WTW, Weilheim, Germany, EU). During a similar period of 7 years (1999-2006), $T$ was previously registered as a single measurement in the same sampling stations, during simultaneous sampling of aquatic macroinvertebrate families. Due to the considerable number of water temperature records registered at each sampling station during this 7-year period, variations in the sampling time of day cover a wide range of daily and seasonal temperatures, meaning that water temperature records can be thought of as representative of the different stretches of the rivers.

Methods for estimating ecological optima and tolerance ranges

\section{The weighted averaging method}

An estimate of the ecological optimum of taxon $j$ with respect to the environmental variable $x$, is the abundance-weighted average, $M_{\mathrm{j}}$, given by

$M_{j}=\frac{\sum_{i=1}^{n} A_{i j} x_{i}}{\sum_{i=1}^{n} A_{i j}}, \quad j=1, \ldots, J$,

where $J$ is the number of different taxa, $n$ is the number of sampling stations, $x_{\mathrm{i}}$ is the observed value of the environmental variable at the sampling station $i$ and $A_{\mathrm{ij}}$ is the abundance of taxon $j$ in the sampling station $i$.

The estimate of the tolerance range of taxon $j$ with respect to the environmental variable $x$ is the abundance-weighted standard deviation, $t_{\mathrm{j}}$, given by

$t_{j}=\frac{\sum_{i=1}^{n} A_{i j}\left(x_{i}-M_{j}\right)^{2}}{\sum_{i=1}^{n} A_{i j}}, \quad j=1, \ldots, J$.

It is difficult to discern if this tolerance alludes to the tolerance range or to the optimum range. In any case, without loss of generality, it is assumed that the optimum range of taxon $j$, with respect to the variable $x$, is the interval

$$
\left(M_{j}-t_{j}, M_{j}+t_{j}\right), \quad j=1, \ldots, J,
$$

whereas the tolerance range is the interval

$\left(M_{j}-2 t_{j}, M_{j}+2 t_{j}\right), \quad j=1, \ldots, J$.

Typically, WA estimates are represented graphically by means of error bars. 


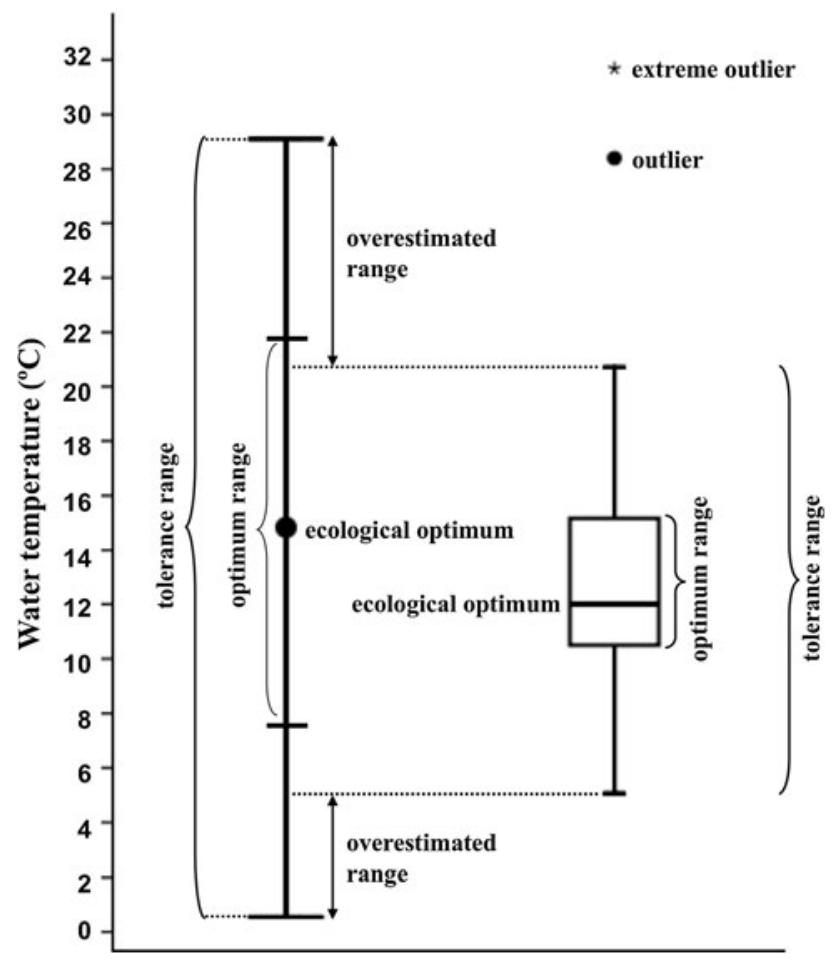

Fig. 2 Water temperature ecological optima, optimum ranges and tolerance ranges for the Rhagionidae family in the JRB derived using the weighted averaging (WA; left) and robust optimum (RO; right) methods. River water temperature was used as the environmental variable, while the absolute abundances of individuals was the abundance at each sample point

\section{The robust optimum method}

For a taxon $j$ and a particular environmental variable $x$, the RO method estimates the ecological optimum as the abundance-weighted median, which is the median of the sequence

$\underbrace{x_{1} \ldots x_{1}}_{A_{1 j}}, \underbrace{x_{2} \ldots x_{2}}_{A_{2 j}}, \ldots \underbrace{x_{n} \ldots x_{n}}_{A_{n j}}$.

The abundance-weighted median is the value $x_{\mathrm{k}}$, such that

$\frac{\sum_{x_{i}<x_{k}} A_{i j}}{\sum_{i=1}^{n} A_{i j}} \leq \frac{1}{2}$ and $\quad \frac{\sum_{x_{i}<x_{k}} A_{i j}}{\sum_{i=1}^{n} A_{i j}} \leq \frac{1}{2}$.

The optimum range estimated by using the RO method is the abundance-weighted interquartile range, IR, given by

$\mathrm{IR}=Q_{3}-Q_{1}$,

where $Q_{1}$ and $Q_{3}$ are the lower and upper quartiles of sequence (5), respectively.

RO estimates are represented graphically by boxplots. The use of box-plots provides a clear distinction between the optimum range and the tolerance range. The RO method estimates the tolerance range as the range delimited by the lower and upper whiskers of an abundance-weighted box-plot. The lower whisker extreme is the first value of sequence (5) greater than $Q_{1}$ $1.5 \mathrm{IR}$, whereas the upper whisker extreme is the first value of sequence (5) lower than $Q_{3}+1.5 \mathrm{IR}$.

An example of the estimates of the ecological optimum, optimum range and tolerance range for water temperature for the Rhagionidae family in the JRB as determined by the application of the WA and RO methods is outlined in Fig. 2.

Comparison of WA and RO methods for estimating the ecological optima, optimum ranges and tolerance ranges: identification of potential biological indicators of global warming

Absolute abundances of families of aquatic macroinvertebrates found in the JRB were selected as data for the identification of potential biological indicators of global warming in this comparison. Specifically, we used estimates of the ecological optima, optimum ranges and tolerance ranges for water temperature to identify potential biological indicators. All these estimates were obtained using the WA and RO methods and were calculated with both real data and simulated data from probable global warming scenarios. This procedure consisted of four steps:

\section{First step}

The water temperature ecological optima, optimum ranges and tolerance ranges for 47 oligostenotherm families of aquatic macroinvertebrates were estimated using the WA and RO methods. Individuals of each family were classified into one of the four zones of the error bars (for WA estimates) and the box-plots (for RO estimates) depending on water temperature data (Fig. 3). The four zones were defined as follows:

Zone 1: lower stress zone The WA method defines zone 1 as the range between the abundance-weighted average minus twice the abundance-weighted standard deviation and the abundance-weighted average minus the abundance-weighted standard deviation. The RO method defines zone 1 as the range between the abundanceweighted minimum over $Q_{1}-1.5$ IR (the lower box-plot whisker) and the abundance-weighted lower quartile.

Zone 2: lower half of the optimum range The WA method defines zone 2 as the range between the abundanceweighted average minus the abundance-weighted standard deviation and the abundance-weighted average. In the RO method, zone 2 is the range between the abundance-weighted lower quartile and the abundanceweighted median (lower half box).

Zone 3: upper half of the optimum range The WA method defines zone 3 as the range between the abundanceweighted average and the abundance-weighted average plus the abundance-weighted standard deviation. The RO method defines zone 3 as the range between the 

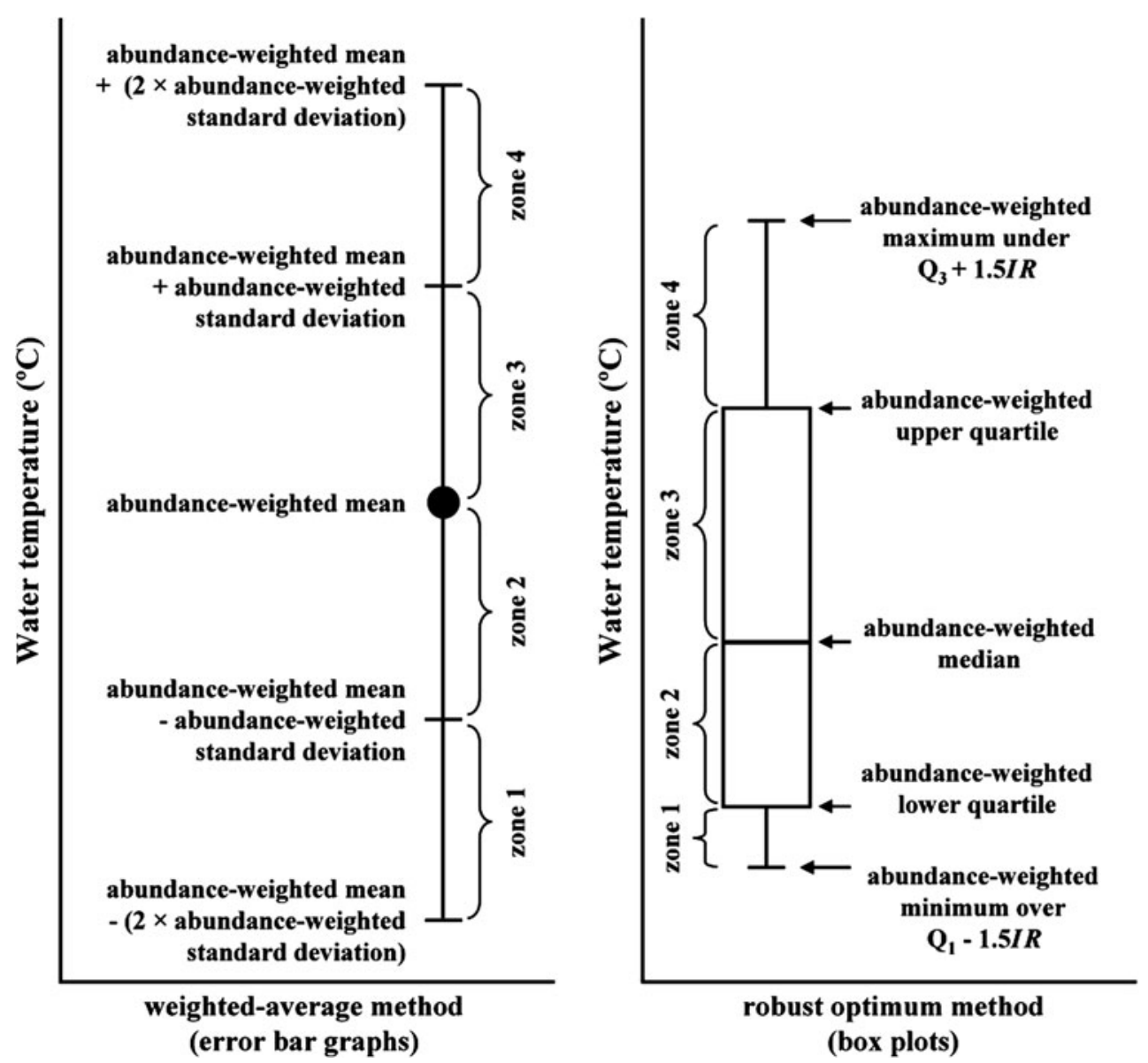

Fig. 3 Definition and graphical representation of the four different zones into which individuals of each family were classified following the application of the WA (left) and RO (right) methods

abundance-weighted median and the abundance-weighted upper quartile (upper half box).

Zone 4: upper stress zone The WA method defines zone 4 as the range between the abundance-weighted average plus the abundance-weighted standard deviation and the abundance-weighted average plus twice the abundanceweighted standard deviation. In the RO method, zone 4 is the range between the abundance-weighted upper quartile and the abundance-weighted maximum under $Q_{3}+1.5$ IR (the upper box-plot whisker).

\section{Second step}

The potential effect of global warming on aquatic macroinvertebrates was simulated by increasing measured water temperature data by $0.5,1,1.5$ and $2{ }^{\circ} \mathrm{C}$, thus covering four probable future global warming scenarios. The classification made in the first step was repeated for each different increase in water temperature and for each macroinvertebrate family (each increase in water temperature was treated independently, i.e. eight new classifications were generated).

\section{Third step}

The effect of global warming was assessed. The original classification of individuals in the 47 oligostenotherm macroinvertebrate families obtained in step 1 was compared with the new classification in step 2 for each water temperature increase. The percentage of individuals that changed with respect to the total number of individuals in the family was calculated. Outliers, identified only with the RO method, were not taken into account in any of these calculations because this kind of data usually show an atypical behaviour that can often be considered a result of measurement errors. As a consequence, we think that its use does not make sense if the identification of potential biological indicators of global warming is the goal. Moreover, under extreme conditions, it is more difficult for aquatic macroinvertebrate families to establish permanent populations because water temperature is critical to the life cycles of aquatic organisms (Allan 1995).

\section{Fourth step}

Potential biological indicators of global warming in the JRB were identified. An oligostenotherm macroinver- 

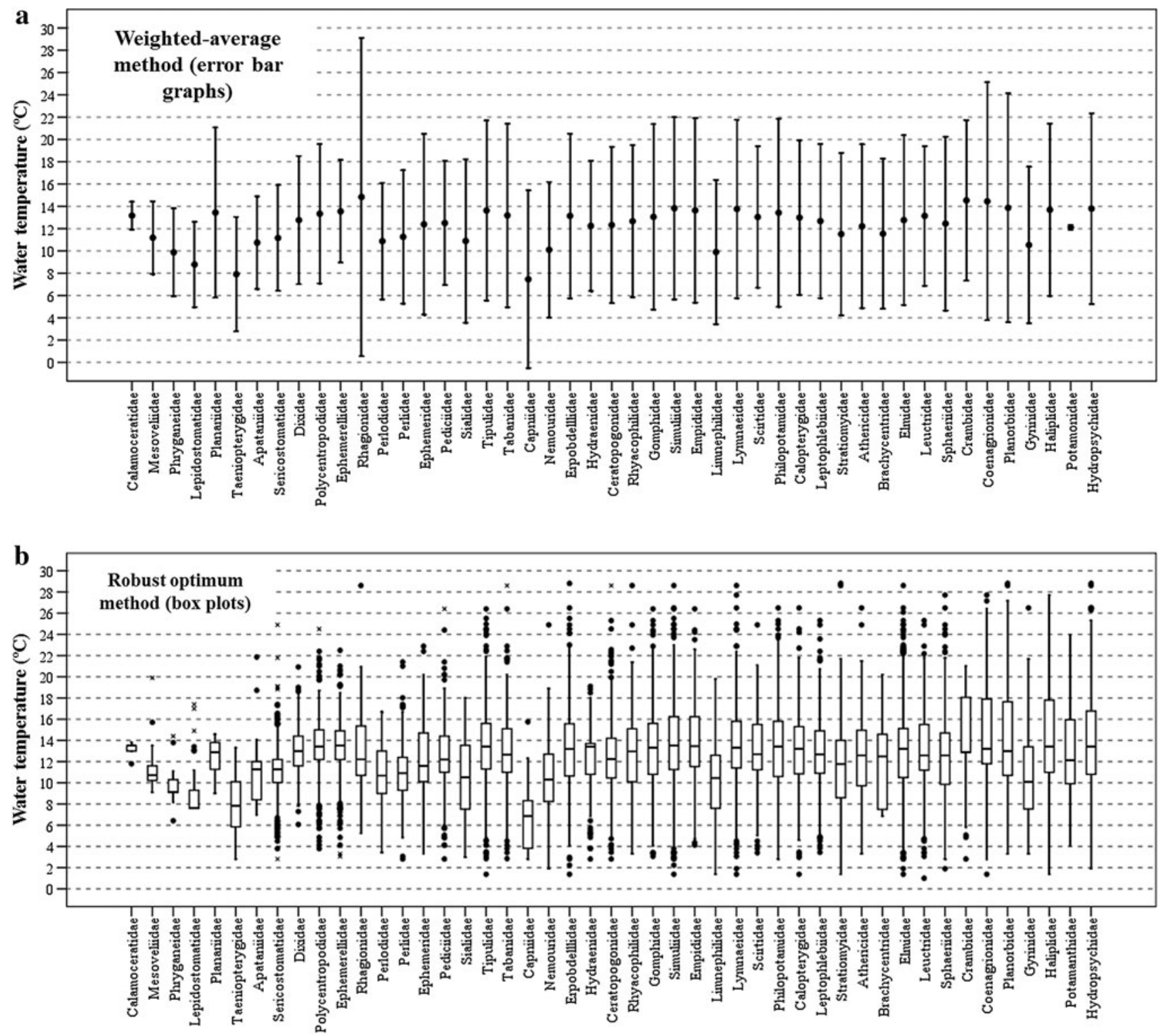

Fig. 4 Representation of water temperature ecological optima, optimum ranges and tolerance ranges for 47 oligostenotherm macroinvertebrate families inhabiting the Júcar River Basin (JRB) obtained from the WA (a) and RO (b) methods

tebrate family was considered to be a potential biological indicator of global warming if it was "seriously affected" by any of the increases in water temperature examined above. A macroinvertebrate family was considered to be "seriously affected" when at least a $75 \%$ of its population changed its classification zone in the box-plot or in the error bar due to the water temperature increase. Macroinvertebrate families that were considered as potential global warming biological indicators in the WA and RO methods for any water temperature increase were selected and the results compared.

All computations, graphical representations and statistical analyses were performed with SPSS 15.0 for Windows (SPSS, Chicago, IL).

\section{Results}

Estimates for the ecological optima, optimum ranges and tolerance ranges for water temperature using the WA and the RO methods on data from 47 oligostenotherm families found in the JRB are shown in Fig. 4. Differences in the estimates are especially clear in some families, such as Phryganeidae, Mesoveliidae, Calamoceratidae, Planariidae, Lepidostomatidae, Capniidae or Rhagionidae.

The results obtained after the simulation of different global warming effects on the abundance of families, as well as the potential biological indicators of water temperature increases, are summarised graphically in Figs. 5 


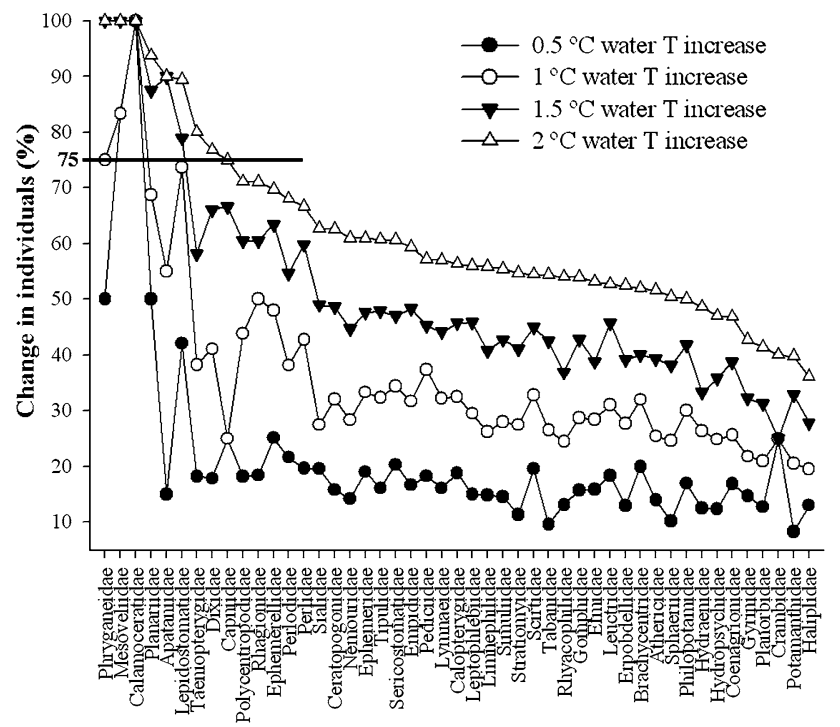

Fig. 5 Results obtained after applying the RO method to the data. The percentage of individuals that changed their classification from one zone to another in the box-plots is represented for each family and for each water temperature increase $\left(0.5,1,1.5\right.$ and $\left.2{ }^{\circ} \mathrm{C}\right)$. The families used in the study are on the $x$-axis. Families in which at least $75 \%$ of the individuals was affected, were considered to be potential biological indicators of global warming

and 6 . Figure 5 shows the results obtained after applying the RO method to the data. The percentage of individuals that changed their classification from one zone to another in the box-plots is represented for each family and for each water temperature increment. The families considered to be potential biological indicators of global warming after using the RO method, for at least one of the water temperature increases, are the first nine located on the $x$-axis (Phryganeidae, Mesoveliidae, Calamoceratidae, Planariidae, Apataniidae, Lepidostomatidae, Taeniopterygidae, Dixidae and Capniidae). Only these nine families were taken into account as the best candidates for continuing with the comparison process in this work.

The percentage of individuals that changed their classification zone in the box-plots (RO method) or in the error bar graphs (WA method) as a result of water temperature increases of $0.5,1,1.5$ and $2{ }^{\circ} \mathrm{C}$ is shown in Fig. 6 for the nine families selected. With a hypothetical water temperature increase of $0.5^{\circ} \mathrm{C}$, the Calamoceratidae and Mesoveliidae families were classified as potential biological indicators of global warming after applying the RO method. The use of the WA method did not identify these families as potential biological indicators (Fig. 6a). The Phryganeidae, Planariidae and Lepidostomatidae families were not considered to be potential biological indicators, although the number of individuals affected after applying the RO method was by no means negligible (Fig. 6a). Half of the individuals in the Phryganeidae and Planariidae families were affected, compared to $42.1 \%$ in the Lepidostomatidae family. In contrast, with the WA method, these percentages were lower, $16.6 \%$ for Phryganeidae, $6.2 \%$ for Planariidae and $10.5 \%$ for
Lepidostomatidae. For a water temperature increase of $1{ }^{\circ} \mathrm{C}$, the Calamoceratidae and Mesoveliidae families were again described as potential biological indicators of global warming using RO and WA methods. The Phryganeidae family was classified as a potential biological indicator only when the RO method was applied (Fig. 6 b). Differences between the two methods in the percentages of affected individuals were undoubtedly observed in the Lepidostomatidae, Planariidae and Apataniidae families. For Lepidostomatidae, the WA method predicted that $47.63 \%$ of the population was affected by the water temperature increase, in comparison to the $73.68 \%$ predicted by the RO method. For Planariidae, these percentages were $25 \%$ and $68.75 \%$, respectively, with the WA method yielding $40 \%$ and the RO method $55 \%$ for the Apataniidae family (Fig. 6b). For a water temperature increase of $1.5^{\circ} \mathrm{C}$, the Calamoceratidae, Mesoveliidae and Lepidostomatidae families were classified as potential biological indicators of global warming following the application of both methods. The Phryganeidae, Apataniidae and Planariidae families were described as potential biological indicators only with the RO method (Fig. 6c). Differences in the Capniidae and Dixidae families appeared when the percentages of affected individuals calculated with the RO method (66.66 \% and $66.07 \%$, respectively) were compared to those estimated by using the WA method $(25 \%$ and $49.12 \%$, respectively). For a water temperature increase of $2{ }^{\circ} \mathrm{C}$, the Calamoceratidae, Mesoveliidae, Phryganeidae, Apataniidae, Lepidostomatidae and Taeniopterygidae families were described as potential biological indicators of global warming following the application of both methods. In contrast, the Planariidae, Dixidae and Capniidae families were classified as potential biological indicators only after the RO method is used (Fig. 6d).

Finally, Fig. 7 shows real estimates (without any water temperature increase) of water temperature ecological optima, optimum ranges and tolerance ranges for families described as potential global warming biological indicators in at least one water temperature increase. $\mathrm{RO}$ estimates were usually narrower than WA estimates (Fig. 7). WA estimates are in many cases excessively wide (Fig. 7). For instance, Fig. 7i shows how one outlier causes the overestimation of the tolerance range in the Capniidae family with the WA method. The overestimation is particularly serious in the lower part, as there were no individuals observed under $2.82{ }^{\circ} \mathrm{C}$, even though the lower limit of the tolerance range predicted by the WA is $-0.51^{\circ} \mathrm{C}$ - an extremely cold value for water temperature not measured in this study (Fig. 7i).

\section{Discussion}

The concepts of ecological optimum, optimum range and tolerance range are used frequently in ecological studies to describe how an environmental variable influences the abundance and the geographical distribution of taxa (Brodersen and Anderson 2002; Sterken et al. 2008). To 

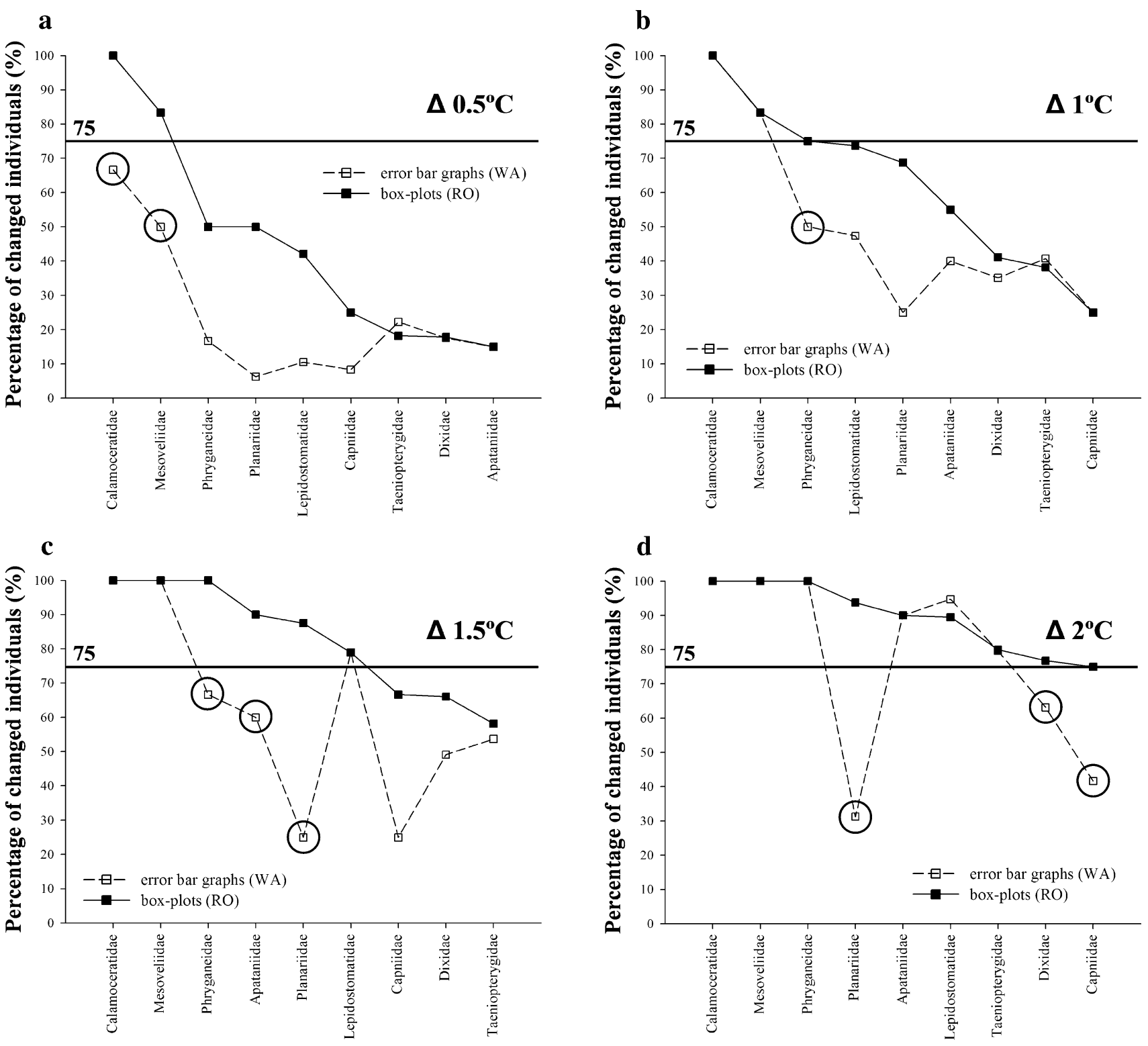

Fig. 6 Comparison between the percentage of individuals showing changes after application of the WA and RO methods with increases of a $0.5, \mathbf{b} 1, \mathbf{c} 1.5$ and $\mathbf{d ~} 2{ }^{\circ} \mathrm{C}$ in water temperature. The circles mark those families identified as biological indicators of global warming as determined by the RO method but not the WA method. The black line at the value of $75 \%$ on the $y$-axis marks

prevent and partially mitigate the consequences of global warming in ecological systems, it is very important to find and describe biological indicators as early sensors of climate change and global warming (Hodkinson 2005; Rivers-Moore et al. 2005; Milner et al. 2009). In fact, the environmental preferences of biological indicators, i.e. their ecological optima as well as their optimum and tolerance ranges, form the basis of climatic envelope models. All habitat-suitability models are inherently linked to the Hutchinsonian definition of the ecological niche, and those based on the environmental envelopes are its direct geometrical application (Hirzel and Arlettaz 2003). The potential impacts of projected climate change

the threshold in the percentage of changed individuals that a family has to exceed in order to be considered as a potential biological indicator of global warming (hence, the potential indicator families are those whose percentage of individuals with change is greater than $75 \%$ )

and global warming on biological taxa are often assessed by using single-taxa bioclimatic envelope models (Heikkinen et al. 2006). The first tests of the predictive accuracy of these models have been made by using past taxa tolerance ranges (Araújo et al. 2005). Therefore, to predict the possible impacts of global warming and climate change on lotic aquatic systems, it is crucial to estimate, represent and understand the ecological optima, optimum ranges and tolerance ranges of biological taxa with respect to environmental variables by means of straightforward computational methods. This is equivalent to estimating, representing and understanding the realised niches of taxa in one dimension. It is thus 

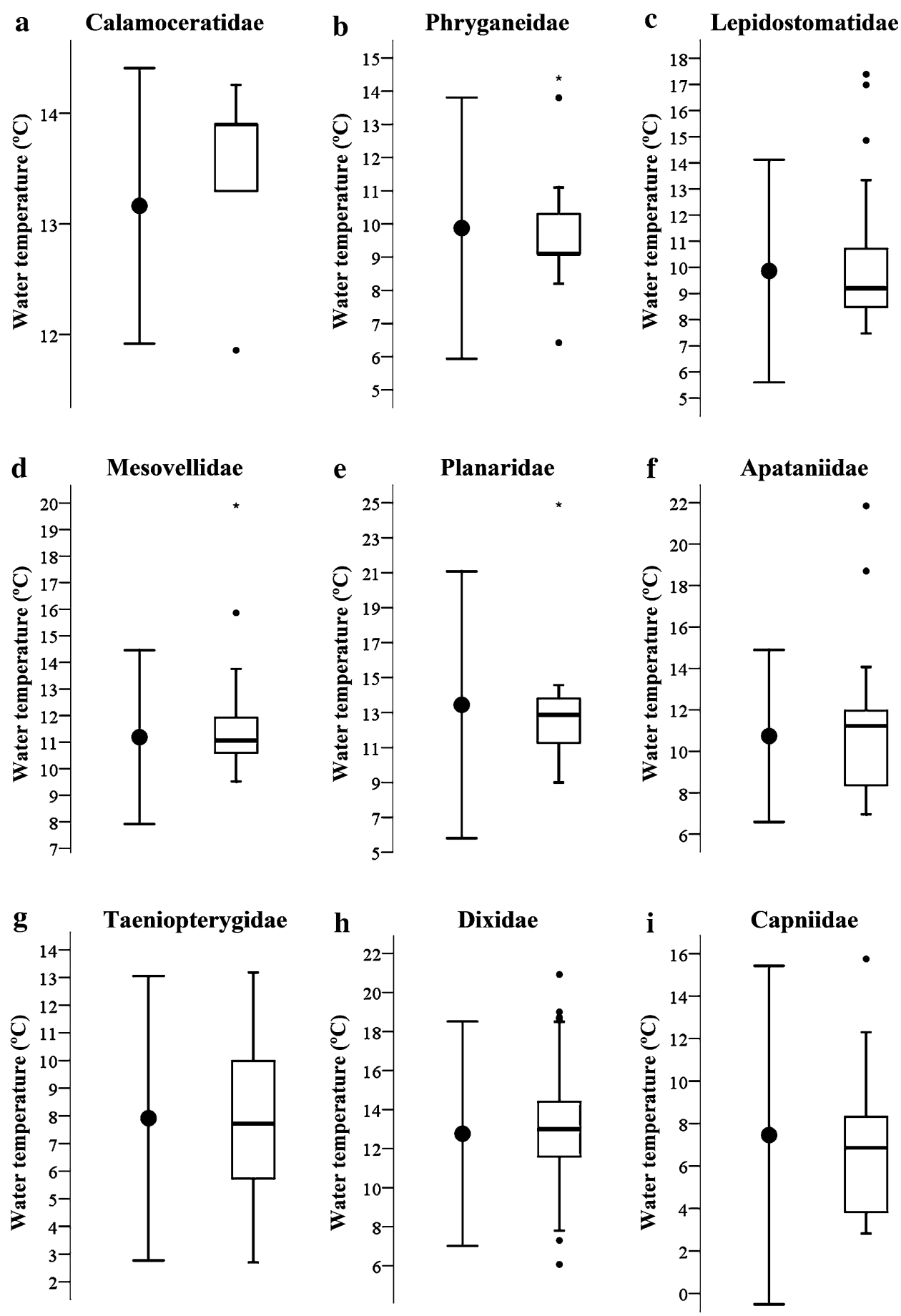

Fig. 7 Estimates resulting from both methods (WA, left side of the subfigures, and RO, right side of the subfigures) for water temperature (without increasing) ecological optimum, optimum range and tolerance range for the families identified as potential biological indicators of global warming

essential to have simple-to-use methods for calculating the ecological optima and the optimum and tolerance ranges, as well as to assess their accuracy and to compare them with one another.

To the best of our knowledge, there are two main classical approaches for calculating and representing the concepts of ecological optimum, optimum range and tolerance range in one dimension. Both approaches are based on the observation that the relationships between taxa abundance and environmental variables are often unimodal (Birks 1995). The first method is the wellknown WA method (Ter Braak and Barendregt 1986). The second method is called the maximum likelihood calibration (MLC) method and uses Gaussian logit response curves to fit the non-linear regression model between taxon abundance and the environmental variable. 
The ecological optimum is defined as the maximum of the fitted curve, while the tolerance range, also called ecological amplitude, is the curve width (Ter Braak and van Dam 1989; Birks et al. 1990; Jeppesen et al. 2001). Graphically, the tolerance range is the size of the curve projection on the $x$-axis of the environmental variable. The MLC method has been widely used in paleolimnology to reconstruct past lake-water $\mathrm{pH}$ conditions (Birks et al. 1990). Ter Braak (1985) proved that estimates of ecological optima and tolerance ranges using both the WA and the MLC methods were similar if the distribution of the environmental variable was uniform over the whole range of occurrence of taxa. Ter Braak and Looman (1986) compared the two methods for nonuniform distributions of the environmental variable and found that they are equally efficient for rare species with a narrow ecological amplitude, but warned about the bias estimates obtained with the WA method in other situations. Ter Braak and van Dam (1989) asserted that, in general, the more sophisticated MLC method performed only slightly better than the WA method. As a consequence, despite its limitations, the WA method has been used broadly to estimate ecological optima due to its simplicity. In fact, bearing in mind this simplicity and how previous studies have noted the lack of significant differences in the behaviour of both methods in the presence of atypical data or asymmetrical distributions, we selected the WA method instead of the MLC method to calculate and represent ecological optima as well as the optimum and tolerance ranges of taxa in this study.

The $\mathrm{RO}$ method is presented in this work as a robust alternative to the classic and widely used WA method. The features of the RO method were checked in the present study. This work also contributes to clarifying the still unsolved problem of having tools to search for sentinels to monitor the impact of global warming on aquatic systems through assessing the tolerance of organisms to natural and anthropogenic disturbances and stressors. We simulated stream water temperature increases in the JRB and found nine oligostenotherm families that could potentially be used as biological indicators by applying the RO method (Fig. 5). The higher the increases in water temperature, the higher the percentages of individuals affected by global warming in each family described and, therefore, the number of families in an endangered situation, in agreement with previous studies (Lehmkuhl 1972; Hogg and Williams 1996; Durance and Ormerod 2007; Chessman 2009). When the WA and the RO methods are compared, the RO method appears to be more accurate and ecologically significant in describing families as potential biological indicators of global warming than the WA method for each of the water temperature increases (Fig. 6). As previously determined (Ter Braak and Looman 1986), we found that the WA method, and consequently its estimates, is affected by at least two well-known main computational problems: overestimation of the optimum and tolerance ranges and bias in the ecological optimum.
The first problem affecting the estimates obtained with the WA method is caused by the presence of outliers and the asymmetry of the distribution of the environmental variable. Both factors inflate the standard deviation and, consequently, overestimate the optimum and tolerance ranges of most families (Fig. 7). This overestimation partially explains why the WA method is less efficient than the RO method in detecting potential biological indicators. The weight of the outliers and the outliers' distance from the box-plot whiskers (the limits of the tolerance range predicted by the RO method) affect the magnitude of the tolerance range overestimation by the WA method. For example, the presence of two upper outliers in the Apataniidae family (at 18.72 and $21.86^{\circ} \mathrm{C}$ ) causes a slight overestimate of the tolerance range due to the low weight of the outliers (Fig. 7f). The abundance (number of individuals) of Apataniidae at $18.72{ }^{\circ} \mathrm{C}$ is 1 and at $21.86^{\circ} \mathrm{C}$ it is 2 . In contrast, the case of the Planariidae family is completely different. The presence of an outlier with a high weight (40 individuals) at $24.9^{\circ} \mathrm{C}$, very far from the upper limit of the tolerance range predicted by the $\mathrm{RO}$ method, $14.58{ }^{\circ} \mathrm{C}$, results in a heavy overestimate $\left(>6^{\circ} \mathrm{C}\right)$ (Fig. 7e). Therefore, it is obvious that just one outlier can impair the results yielded by the WA method. If there are no outliers, the RO method would work in a similar way to the WA method, as in the case of the Taeniopterygidae family, with similar estimates resulting from the use of both methods (Fig. 7g). Moreover, the overestimation problem has another consequence. While the results after the application of the RO method offer a warning on how some families are affected by global warming (e.g. Phryganeidae, Planariidae and Lepidostomatidae after a $0.5{ }^{\circ} \mathrm{C}$ increment), the results from the application of the WA method do not offer a similar warning (Fig. 6a). This is usually the case for those families that are not classified as potential global warming biological indicators at low water temperature increases but show major differences between the percentage of affected individuals calculated using the WA method and the percentage of affected individuals calculated using the RO method. These families are usually described as biological indicators at higher water temperature increases by the RO method, whereas they are lost in this context if the WA method is used. Consequently, differences in the number of affected individuals between the two methods are by no means negligible and the information provided by the RO method seems to be, ecologically speaking, more useful and accurate for identifying potential biological indicators of global warming.

The second, but no less important, problem with the WA method is the abundance-weighted average bias. Upper and lower outliers push the abundance-weighted average up and down, causing a bias and, consequently, displacing the ecological optimum. For instance, in the Lepidostomatidae family the abundance-weighted average is biassed upward due to the presence of upper outliers (Fig. 7c). In contrast, in the Taeniopterygidae 
family, the abundance-weighted average is not biassed because there are no outliers (Fig. 7g). From an ecological point of view, the displacement of the ecological optimum is not desirable because a taxon can be considered as a potential indicator of global warming when it really should not be.

The aforementioned problems do not become apparent in the RO method. This is explained computationally by the robust properties of the abundanceweighted median and the abundance-weighted interquartile range (Huber 1964). In the simple model of location, the median is the most robust estimator for any fraction of contamination in terms of maximum bias (it minimises maximum bias). The median has a breakdown point of $50 \%$, while the mean has a breakdown point of $0 \%$. As a consequence, the RO method is less affected by the presence of outliers and the asymmetry in the distribution of environmental variables than the WA method. Therefore, even with the presence of outliers, the RO estimates provide narrower and more accurate ecological tolerance ranges, a very useful aspect when looking for potential biological indicators in limnological studies (Reed 1998; Midgley et al. 2002; Meador et al. 2008; Penning et al. 2008a; Penning et al. 2008b). Hence, we propose that the RO method should be used for estimating the environmental preferences of taxa instead of the WA method and, consequently, for identifying potential biological indicators.

We used a family-level taxonomic resolution in this study, in keeping with the procedures adopted by Spanish authorities for monitoring rivers to fulfill the requirements of the EU-WFD (EC 2000). This taxonomic resolution has also been chosen by others to rank sites according to their conservation values and assessed by the biodiversity patterns they exhibit (Heino and Soininen 2007; Munné and Prat 2009). The efficient management of freshwater resources, including the conservation of aquatic ecosystem services and biodiversity, is one of the major challenges facing modern society. Such management requires tools to assess the ecological quality of sites and to detect and quantify the effects of several natural and anthropogenic disturbances and stressors (Beketov et al. 2009). Among these tools, the use of biological communities as sentinels or indicators of change is widespread. There is an intense debate in the literature on the taxonomic resolution that must be used to assess the biodiversity and ecological integrity of aquatic systems for conservation, management and restoration purposes (Törnblom et al. 2011). Although a discussion of this latter debate is beyond the scope of this work, we are aware that intrafamilial variation can be important when the main objective is to accurately identify biological indicators, because the higher the taxonomic resolution, the higher the level of detection of biological change (Haase and Nolte 2008). Consequently, the use of a lower taxonomic resolution is recommended. However, when the diversity is not high and the spatial scale of the study is large, the use of a family-level taxonomic resolution can reproduce the ecological patterns and properties shown by species-level or genus-level taxonomic resolution approaches (Marshall et al. 2006; Bates et al. 2007; Heino and Soininen 2007; Chessman 2012).

Finally, it is well known that every taxon is restricted to a certain temperature range, although this does not mean that water temperature should be considered the ultimate determinant of where a taxon lives. In fact, it is equally likely that other factors set range limits, and the taxon has adapted to the conditions where it occurs. In any case, temperature unquestionably sets limits on where a taxon can live (Allan 1995). Nonetheless, this study should be considered only as a theoretical approximation to introduce a new method for computing and representing the ecological optima as well as the optimum and tolerance ranges of taxa, and not as a theoretical work to unravel the factors that best determine the distribution of taxa in running aquatic systems. We consider this work only as a first step towards experimental testing in the future of its conclusions on the appropriateness of the RO method for identifying potential biological indicators of global warming. By carrying out a field experiment as a second step, we will be able to assess the importance of the water temperature as a factor for controlling the range of taxa and, consequently, the ranges of potential biological indicators of global warming or, perhaps, the significance of other factors that should also be considered in order to achieve the goals established by the EU-WFD (EC 2000).

\section{Conclusion}

This study introduces the use of the RO method to estimate ecological optima, tolerance ranges and optimum ranges for taxa in limnological studies. By comparing these estimates in data for macroinvertebrate families living in the JRB (eastern Spain) after the application of the RO method and the classic WA method, our results support the well-known fact that the presence of outliers and the asymmetry of the distribution of the environmental variable negatively affect WA method estimates and, consequently, can also affect the predictions obtained after using this method, as already proposed (Birks et al. 1990). The RO method is as simple to implement as the WA method, is easy to represent graphically and is more robust for estimating ecological optima, optimum ranges and tolerance ranges. It also provides a more realistic representation of the distribution of data than the WA method, particularly in atypical situations. In addition, the box-plots show a clear distinction between the optimum range and the tolerance range, whereas the error bars do not. As a consequence, the RO method seems to be a good alternative to the WA method in limnological studies. Moreover, the higher efficiency in the detection of potential biological indicators (sentinels) following the application of the RO method could help predict the 
possible effects of global warming on freshwater ecosystems, and hence, improve the management programmes designed to achieve a good ecological status of water bodies according to the EU-WFD (EC 2000).

Acknowledgments We would like to thank the Júcar River Basin (JRB) staff for providing data on aquatic macroinvertebrates and water temperature. This study was funded by the Spanish General Directorate of Water (Ministry of Agriculture, Food and Environment) as part of a project commissioned to the Centre for Hydrographic Studies (CEDEX) to study the impact of climate change on freshwater resources in Spain.

\section{References}

Abell R (2002) Conservation biology for the biodiversity crisis: a freshwater follow-up. Conserv Biol 16:1435-1437

Allan JD (1995) Stream ecology: structure and function of running waters. Kluwer, Dordrecht

Araújo MB, Whittaker RJ, Ladle R, Erhard M (2005) Reducing uncertainty in projections of extinction risk from climate change. Global Ecol Biogeogr 14:529-538

Bates CR, Scott G, Tobin M, Thompson R (2007) Weighing the costs and benefits of reduced sampling resolution in biomonitoring studies: perspectives from the temperate rocky intertidal. Biol Conserv 137:617-625

Beketov MA, Foit K, Schäfer RB, Schriever CA, Sacchi A, Capri E, Biggs J, Wells C, Liess M (2009) SPEAR indicates pesticide effects in streams - comparative use of species- and family-level biomonitoring data. Environ Pollut 157:1841-1848

Birks HJB (1995) Quantitative palaeoenvironmental reconstructions. In: Maddy D, Brew JS (eds) Statistical modelling of quaternary science data. Quaternary Research Association, Cambridge, pp 161-254

Birks HJB, Line JM, Juggins S, Stevenson AC, Ter Braak CJF (1990) Diatoms and pH reconstruction. Philos Trans R Soc B 327:263-278

Bradshaw EG, Anderson NJ, Jensen JP, Jeppesen E (2002) Phosphorus dynamics in Danish lakes and the implications for diatom ecology and palaeoecology. Freshw Biol 47:1963-1975

Brodersen KP, Anderson NJ (2002) Distribution of chironomids (Diptera) in low arctic West Greenland lakes: trophic conditions, temperature and environmental reconstruction. Freshw Biol 47:1137-1157

Cairns J, McCormick PV, Niederlehner BR (1993) A proposed framework for developing indicators of ecosystem health. Hydrobiologia 263:1-44

Chessman BC (2009) Climatic changes and 13-year trends in stream macroinvertebrate assemblages in New South Wales, Australia. Glob Change Biol 15:2791-2802

Chessman BC (2012) Biological traits predict shifts in geographical ranges of freshwater invertebrates during climatic warming and drying. J Biogeogr 39:957-969

Durance I, Ormerod SJ (2007) Climate change effects on upland stream macroinvertebrates over a 25 -year period. Glob Change Biol 13:942-957

EC (2000) Directive 2000/60/EC of the European Parliament of the Council of 23rd October 2000 establishing a framework for community action in the field of water policy. Official $\mathbf{J}$ Eur Commun L327:1-72

Estrela T, Fidalgo A, Fullana J (2004) Júcar Pilot River Basin: Provisional Article 5 Report: Pursuant to the Water Framework Directive. Ediciones de la Confederación Hidrográfica del Júcar, Ministerio de Medio ambiente, Valencia

Haase R, Nolte U (2008) The invertebrate species index (ISI) for streams in southeast Queensland, Australia. Ecol Indic 8:599-613

Heikkinen RK, Luoto M, Araújo MB, Virkkala R, Thuiller W, Sykes MT (2006) Methods and uncertainties in occurrence with spatial reserve design. J Appl Ecol 41:252-262
Heino J, Soininen J (2007) Are higher taxa adequate surrogates for species-level assemblage patterns and species richness in stream organisms? Biol Conserv 137:78-89

Hirzel AH, Arlettaz R (2003) Environmental-envelope based habitat-suitability models. In: Manly BJC (ed) Proceedings of the 1st conference on resource selection by animals, Laramie, pp 21-34

Hodkinson ID (2005) Terrestrial insects along elevation gradients: species and community responses to altitude. Biol Rev 80:489-513

Hogg ID, Williams DD (1996) Response of stream invertebrates to a global-warming thermal regime: an ecosystem-level manipulation. Ecology 77:395-407

Holden PB, Mackay AW, Simpson GL (2008) A Bayesian palaeoenvironmental transfer function model for acidified lakes. J Paleolimnol 39:551-566

Huber PJ (1964) Robust estimation of location parameters. Ann Stat 35:73-101

Huggett RJ (2004) Fundamentals of biogeography. Routledge, London

Hutchinson GE (1957) Population studies: animal ecology and demography. Cold Spring Harb Symp 22:415-427

IPCC (2007) Summary for policymakers: the physical science basis. Contribution of Working Group I to the Fourth Assessment Report of the Intergovernmental Panel on Climate Change. Cambridge University Press, Cambridge

Jáimez-Cuéllar P, Vivas S, Bonada N, Robles S, Mellado A, Álvarez M, Avilés J, Casas J, Ortega M, Pardo I, Prat N, Rieradevall M, Sáinzcantero CE, Sánchez-Ortega A, Suárez ML, Toro M, Vidal-Albarca MR, Zamora-Muñoz C, Alba-Tercedor J (2002) Protocolo GUADALMED (PRECE). Limnetica 21:187-204

Jeppesen E, Leavitt P, de Meester L, Jensen JP (2001) Functional ecology and palaeolimnology: using cladoceran remains to reconstruct anthropogenic impact. Trends Ecol Evol 16:191-198

Lehmkuhl DM (1972) Change in thermal regime as a cause of reduction of benthic fauna downstream of a reservoir. J Fish Res Board Can 29:1329-1332

MARM (2008) Orden ARM/2656/2008, de 10 de septiembre, por la que se aprueba la Instrucción de Planificación Hidrológica. BOE n ${ }^{\circ} 229$ de 22 de septiembre, pp 38472-38582

Marshall CJ, Stewart AL, Harch BD (2006) Taxonomic resolution and quantification of freshwater macroinvertebrate samples from an Australian dryland river: the benefits and costs of using species abundance data. Hydrobiologia 572:171-194

Meador MR, Carlisle DM, Coles JF (2008) Use of tolerance values to diagnose water-quality stressors to aquatic biota in New England streams. Ecol Indic 8:718-728

Midgley GF, Hannah L, Millar D, Rutherford MC, Powrie LW (2002) Assessing the vulnerability of species richness to anthropogenic climate change in a biodiversity hotspot. Global Ecol Biogeogr 11:445-451

Miettinen JO, Simola H, Gronlund E, Lahtinen J, Niinioja R (2005) Limnological effects of growth and cessation of agricultural land use in Ladoga Karelia: sedimentary pollen and diatom analyses. J Paleolimnol 34:229-243

Milner AM, Brown LE, Hannah DM (2009) Hydroecological effects of shrinking glaciers. Hydrol Process 23:62-77

Munné A, Prat N (2009) Use of macroinvertebrate-based multimetric indices for water quality evaluation in Spanish Mediterranean rivers: an intercalibration approach with the IBMWP index. Hydrobiologia 628:203-225

Negro AI, de Hoyos C (2005) Relationships between diatoms and the environment in Spanish reservoirs. Limnetica 24:133-144

Oksanen J, Läärä E, Huttunen P, Meriläinen J (1988) Estimation of $\mathrm{pH}$ optima and tolerances of diatoms in lake sediments by the methods of weighted averaging, least squares and maximum likelihood, and their use for the prediction of lake acidity. J Paleolimnol 1:39-49

Penning WE, Dudley B, Mjelde M, Hellsten S, Hanganu J, Kolada A, van den Berg M, Poikane S, Phillips G, Willby N, Ecke F (2008a) Using aquatic macrophyte community indices to define the ecological status of European lakes. Aquat Ecol 42:253-264 
Penning WE, Mjelde M, Dudley B, Hellsten S, Hanganu J, Kolada A, van den Berg M, Poikane S, Phillips G, Willby N, Ecke F (2008b) Classifying aquatic macrophytes as indicators of eutrophication in European lakes. Aquat Ecol 42:237-251

Reed JM (1998) A diatom-conductivity transfer function for Spanish salt lakes. J Paleolimnol 19:399-416

Rivers-Moore NA, Jewitt GPW, Weeks DC (2005) Derivation of quantitative management objectives for annual instream water temperatures in the Sabie River using a biological index. Water SA 31:473-482

Schoenfelder IJ, Gelbrecht J, Schoenfelder J, Steinberg CEW (2002) Relationships between littoral diatoms and their chemical environment in northeastern German lakes and rivers. J Phycol 38:66-82

Smith TM, Smith RL (2009) Elements of ecology. Cummings, San Francisco

Sterken M, Verleyen E, Sabbe K, Terryn G, Charlet F, Bertrand S, Boes X, Fagel N, de Batist M, Vyverman W (2008) Late quaternary climatic changes in southern Chile, as recorded in a diatom sequence of Lago Puyehue (40 degrees 40'S). J Paleolimnol 39:219-235

Ter Braak CJF (1985) Correspondence analysis of incidence and abundance data: properties in terms of a unimodal response model. Biometrics 41:859-873

Ter Braak CJF, Barendregt LG (1986) Weighted averaging of species indicator values: its efficiency in environmental calibration. Math Biosci 78:57-72
Ter Braak CJF, Looman CWN (1986) Weighted averaging logistic regression and the Gaussian response model. Vegetatio 65:3-12

Ter Braak CJF, van Dam H (1989) Inferring pH from diatoms: a comparison of old and new calibration methods. Hydrobiologia 178:209-224

Törnblom J, Roberge JM, Angelstam P (2011) Rapid assessment of headwater stream macroinvertebrate diversity: an evaluation of surrogates across a land-use gradient. Fund Appl Limnol 178:287-300

Verbitsky VB, Verbitskaya TI (2007) Ecological optimum of ectothermic organisms: static-dynamical approach. Dokl Akad Nauk 416:830-832

Wetzel RG (2001) Limnology. Academic, San Diego

Woodward G, Perkins DM, Brown LE (2010) Climate change and freshwater ecosystems: impacts across multiple levels of organization. Philos Trans R Soc B 365:2093-2106

Wright JW, Davies KF, Lau JA, McCall AC, McKay JK (2006) Experimental verification of ecological niche modeling in a heterogeneous environment. Ecology 87:2433-2439

Yang X, Anderson NJ, Dong X, Shen J (2008) Surface sediment diatom assemblages and epilimnetic total phosphorus in large, shallow lakes of the Yangtze floodplain: their relationships and implications for assessing long-term eutrophication. Freshw Biol 53:1273-1290 